\title{
Como controlar a los niños hiperactivos dentro del salón de clase
}

\section{How to control hyperactive children in the classroom}

Lcda. Vicenta Melania Serrano Galarza, Msc. ${ }^{1}$, Prof. Luis Aníbal Torres Jiménez.. ${ }^{2}$, Lcda. Maura María Cedeño Salavarría. ${ }^{3} \&$ Lcda. Kira Gipssi Sarmiento Espinoza. ${ }^{4}$

Recibido: 25-06-2020 /Aceptado: 28-07-2020 / Publicado: 07-08-2020

\begin{abstract}
.
DOI: https://doi.org/10.33262/concienciadigital.v3i3.1.1368

Students with Attention Deficit and Hyperactivity (ADHD) react immediately to any stimuli that are presented around them since their attention is very short and this is the reason why they make mistakes with much more frequency than children who reflect. The teacher must know the strategies that can be used within the process of learning development in those students, in such a way that he can optimize the different behaviors. The learning capacity that they possess should be taken into account in the learning process. Undoubtedly, the majority of children who have these inappropriate behaviors have difficulties in learning, therefore their way of behaving is not that they want to act that way but rather they cannot control themselves. When children are restless, they release hormones along with racing emotions of failure. Every time they execute a reaction such as throwing objects, tantrums, aggression, escape, tantrums among others. These behaviors do not mean that we should tolerate them but that we should be understanding with them and in turn help them in the most convenient way. It should be noted that the majority of these aggressive children repeatedly regret their attitudes and say they will not do it again when we make them see reason. However, each time they return to perform the same intolerable behaviors that express great concern when realizing that they cannot change and also because they did.
\end{abstract}

\footnotetext{
${ }^{1}$ Universidad Cesar Vallejo - UCV. Piura-Perú., Guayaquil -Guayas- Ecuador., vicentamsg@ @otmail.com

${ }^{2}$ Escuela de Educación Básica - Mons. José María Macías, Espíndola-Loja- Ecuador., latj1986@hotmail.com

${ }^{3}$ Unidad Educativa Salinas - , Salinas -Santa Elene- Ecuador., dinorka07@hotmail.com

${ }^{4}$ Distrito 09D02 Ministerio de Educación, Guayaquil -Guayas- Ecuador., kira.sarmiento@educacion.gob.ec
} 
Keywords: Children, Hyperactive, Classroom, Attention

\section{Resumen.}

Los estudiantes con Déficit de Atención e Hiperactividad (TDAH) reaccionan inmediatamente a cualquier estímulos que se les presentan a su alrededor ya que su atención es muy corta y este es el motivo por el cual realizan con mucha frecuencia más faltas que los niños que reflexionan. El docente debe conocer las estrategias que puede utilizar dentro del proceso del desarrollo de aprendizaje en aquellos estudiantes, de tal manera que pueda optimizar las diferentes conductas. Se debe tomar en cuenta la capacidad de aprendizajes que ellos poseen en el proceso de aprendizaje. Sin duda alguna los niños que tienen estas conductas inadecuadas en su gran mayoría tienen dificultades para aprender por lo tanto su forma de comportarse no es que quieran actuar de esa manera sino más bien no pueden controlarse. Cuando los niños están inquietos liberan hormonas juntamente con emociones aceleradas de fracaso. Cada vez que ejecutan alguna reacción como lanzar objetos, rabietas, agresión, escape, berrinches entre otros. Estos comportamientos no significan que debemos tolerarles sino que debemos ser comprensivos con ellos y a su vez ayudarles de la manera más conveniente. Cabe indicar que la mayoría de estos niños agresivos varias veces se arrepientes de sus actitudes y dicen no volverlo hacer cuando le hacemos entrar en razón. Sin embargo cada vez vuelven a realizar las mismas conductas intolerables que expresan una gran preocupación al darse cuenta que no pueden cambiar y también porque lo hicieron.

Palabras claves: Niños, Hiperactivos, Salón de Clase, Atención

\section{Introducción.}

La hiperactividad son trastornos de comportamientos constantes, tendencia a distraerse inmediatamente, impulsivos, difícilmente pueden concentrarse, muy agresivos y otras conductas parecidas. Se refiere a los niños que mantienen constante movimiento motor sin que tenga un propósito (Still, 1902) Caminan de un lugar a otro, intentan empezar una actividad pero inmediatamente le dejan luego continúan con otra y la dejan incompleta.

Estos comportamientos son constantes cuando se encuentran en compañía de personas en especial con aquellas que no tienen confianza. Mientras que cuando se encuentran solos las actividades son menos.

\section{¿Tienes un niño hiperactivo?}

Identifica sus características según Still.

Estos niños son: 
- Son problemáticos.

- Tienen un espíritu destructivo.

- Fuertes en los castigos.

- Inquietos y nerviosos.

- Difíciles de educar.

- Pocas veces mantienen atención.

- Tiene problemas de rendimiento escolar.

- Tienen cociente intelectual normal.

- Impulsivos y desobedientes.

- Poco realizan lo que sus docentes o padres le dicen.

- Realizan lo contrario de lo que se les indica.

- Son testarudos y caprichosos.

- Son insistentes a los que ellos quieren.

Todos estos comportamientos unidos hacen provocar nerviosismo en el hogar y en el sistema educativo.

Estos niños no pueden estar tranquilos durante la clase o en alguna tarea designada. Es normal que los niños durante el receso escolar estén en constantes movimiento del juego.

\section{¿Por qué son hiperactivos los niños?}

Se deduce afecta a un 3\% a los niños menores a 7 años y por lo general se presenta más en las niñas. Según (Tredgold, 1914) informa que son muchas las causas que intervienen.

\section{Causas principales}

- Disfunción cerebral mínima.

- Encefalitis letárgica que afecta al área del comportamiento, de ahí la constante hipercinesia compensatoria.

- Explosivos en actividades que ellos desean hacer.

- Indispuestos a estar tranquilos.

\section{Hiperactividad de acuerdo a la edad}

\section{0 - 2 años:}

- Aumenta las actividades durante el sueño.

- Mantiene dificultades para dormir, mientras come.

- Tiene poco sueño.

- Resiste a los cuidados diarios.

- Reacciona a los estímulos de audición.

\section{2 - 3 años}

- Poco lenguaje expresivo.

- Su actividad motriz es extremada.

- No teme al peligro y a sufrir varios accidentes: 
4 - 5 años:

- Mantiene problemas al adaptarse socialmente.

- Son desobedientes.

- No siguen normas.

\section{6 años en adelante:}

- Son impulsivos

- Tiene déficit de atención.

- Tiene fracaso escolar.

\section{ESTRATEGIAS PARA CONTROLAR A NIÑOS HIPERACTIVOS}

Estas estrategias ayudarán a controlar a los niños tanto en el hogar como en el salón de clase.

Fijar normas de compromisos: Crear normas de compromisos dentro del hogar y salón de clase juntamente con ellos, dando a conocer las consecuencias si no se llegaren a cumplir. Estas normas de compromisos deben ser recordadas como un mínimo por 21 días y estar colocadas en un lugar visible.

Convocar a reflexionar: El docente o padre de familia siempre debe realizar preguntas, invitando a pensar al niño para responder en el tiempo que sea necesario. Es necesario decirle que no den respuesta a la rápida sino que se piensen bien antes de responder.

Recordar turno de la palabra: Solicitar al niño que escriba lo que desea decir para que no se olvide. De esta manera el niño aprenderá a respetar el turno de la palabra.

Guiarle para crear alternativas: Hacer reflexionar al niño a través de diferentes medios (videos cortos, lecturas, ejemplos del diario vivir entre otros). Esto servirá de evaluación de su conducta sin que él se sienta culpable, luego solicitarle que otras alternativas puede tomar para resolver aquel inconveniente.

Participación: Pedir entre los compañeros que sirvan de modelos para dramatizar las instrucciones solicitadas.

Supervisar: Estar verificando continuamente durante el receso, hora de salida, fiesta, ejercicios, etc.

Fortalecer el lenguaje apropiado: Realizar el autocontrol durante el niño realiza las tareas verbales, para ir corrigiendo las palabras apropiadas que debe expresarse. Para esto es necesario motivarle que digan en voz alta lo que piensan e ir guiándoles a controlar su vocabulario sin que el piense que estamos controlando su conducta.

Reforzar el comportamiento: Cada día se debe reforzar las conductas planteadas en las normas de compromisos creadas con el niño. También es necesario presentar los avances de aprendices de los niños.

Conservar la serenidad: Cuando se presentan casos, rabietas, insultos, etc. Los docentes y padres de familia es muy importante conservar la serenidad. 
Dialogar acerca de las conductas inadecuadas: Cuando observamos conductas inadecuadas en el niño debemos evitar las comparaciones, hablar en público, decir expresiones negativas. Debemos aconsejar en privado dándole a conocer que las conductas inadecuadas tienen sus consecuencias graves, y si acaso ha insultado buscar la manera que él pueda pedir perdón a quien agredió, siempre esperando que primero se tranquilice. Hacerle contar del 1 al 10 o también hacerle respirar y botando el aire por la boca, de esa forma el niño se tranquilizará más rápido.

Mantener la autoestima: Debemos ser prudentes en nuestras expresiones para no bajar el autoestima de los demás.

Actividades de relajación: Es muy importante después de ciertas tareas que hayan realizado los niños, realizar actividades de relación como la técnica de respiración: se inspira muy profundo contando del 1 al 10 y luego se expira lentamente, también se gira la cabeza lentamente de izquierda a derecha por 5 veces, luego mover la cabeza adelante y hacia atrás lentamente por 5 veces, esta técnica es muy apropiada para todas las edades.

A través de investigación queremos llegar a los docentes y padres de familia con una herramienta adecuada de estrategias que les servirá mejorar y controlar la conducta inadecuada de los niños que tiene hiperactividad.

\section{Conclusiones}

- En conclusión los niños que sufren hiperactividad tienen muchas dificultades para desenvolverse en el medio social que les rodea y poco responden en el aprendizaje escolar. Si no se los trata a tiempo pueden hasta perder el año escolar.

- A través de este estudio se procede a dar una serie de estrategias para ayudar a controlar a los niños hiperactivos tanto en el hogar como dentro del salón de clase. Por lo tanto se motiva a los padres de familia y docentes a identificar la hiperactividad de sus niños de acuerdo a la edad cronológica y poner en práctica las estrategias sugeridas ya que éstas les servirán de gran ayuda para controlar las conductas inadecuadas que tienen sus niños: 1. Fijar normas de compromisos, 2. Convocar a reflexionar, 3. Recordar turno de la palabra, 4. Guiarle para crear alternativas, 5. Participación, 6. Supervisar, 7. Fortalecer el lenguaje apropiado, 8. Reforzar el comportamiento, 9. Conservar la serenidad, 10. Dialogar acerca de las conductas inadecuadas 11. Mantener la autoestima 12. Actividades de relajación

\section{Referencias bibliográficas}

Amutio, A. (2002) Estrategias de manejo del estrés: el papel de la relajación. C. Med. Psicosom, No 62 / 63.

Arguello, B. (2016) Estrategias metodológicas que facilitan el proceso de enseñanza aprendizaje de la Geografía e Historia en la Educación Secundaria Básica. 
Banús Llort, B. (2011)"Controlar la impulsividad en niños".

Banús Llort, B. (2011)"Controlar la impulsividad en niños".

Barbarro, R. (2019) Qué es el fracaso escolar: causas, tipos y consecuencias

Cruz, M. (2017) Estrategias metodológicas para la Enseñanza-Aprendizaje con Enfoque Aprender en Libertad.

Dris, M. (2010). Actividades de relajación en Educación Infantil y Primaria. Innovación y experiencias educativas, 34 .

Echeverría, S. (1998). La voz infantil: Educación y reeducación. Editorial CEPE.

Iliana, R. (2015) Actitudes conflictivas

Matías, R. (2018) Estrategias metodológicas (definición y tipos)

Morán, L. (2016) Trastornos del aprendizaje hiperactividad.

Vélez, C. (2012) Trastorno por déficit de atención e hiperactividad (TDAH), una problemática a abordar en la política pública de primera infancia en Colombia.

Willian, C. (2018) Trastornos depresivos 
PARA CITAR EL ARTÍCULO INDEXADO.

Serrano Galarza, V. M., Torres Jiménez, L. A., Cedeño Salavarría, M. M., \& Sarmiento Espinoza, K. G. (2020). Como controlar a los niños hiperactivos dentro del salón de clase. ConcienciaDigital, 3(3.1), 88-94. https://doi.org/10.33262/concienciadigital.v3i3.1.1368

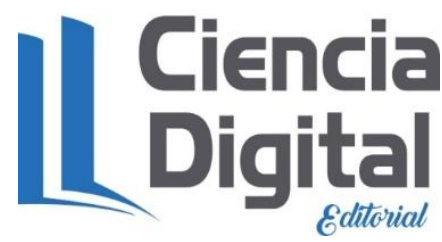

El artículo que se publica es de exclusiva responsabilidad de los autores y no necesariamente reflejan el pensamiento de la Revista Conciencia Digital.

El artículo queda en propiedad de la revista y, por tanto, su publicación parcial y/o total en otro medio tiene que ser autorizado por el director de la Revista Conciencia Digital.

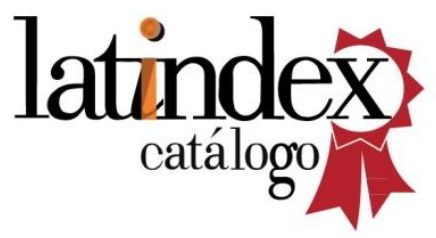

Conciencia

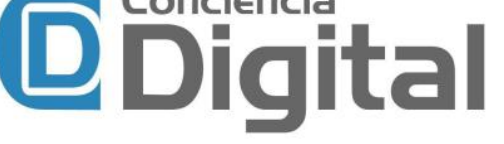

